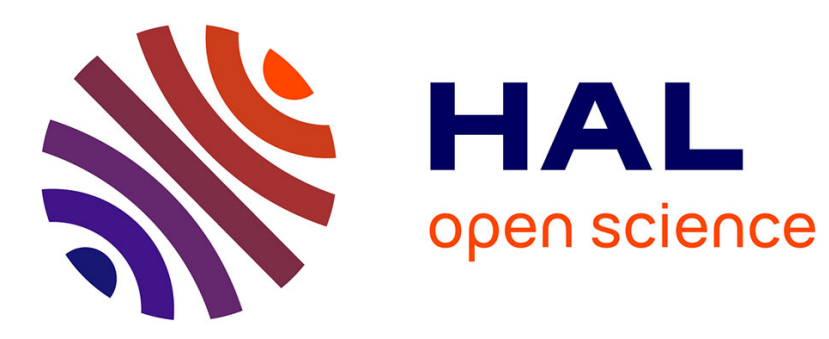

\title{
Steroid and nonsteroidal anti-inflammatory drugs, cognitive decline, and dementia.
}

Marie-Laure Ancelin, Isabelle Carrière, Catherine Helmer, Olivier Rouaud, Florence Pasquier, Claudine Berr, Isabelle Chaudieu, Karen Ritchie

\section{To cite this version:}

Marie-Laure Ancelin, Isabelle Carrière, Catherine Helmer, Olivier Rouaud, Florence Pasquier, et al.. Steroid and nonsteroidal anti-inflammatory drugs, cognitive decline, and dementia.. Neurobiology of Aging, 2012, 33 (9), pp.2082-90. 10.1016/j.neurobiolaging.2011.09.038 . inserm-00782581

\section{HAL Id: inserm-00782581 https://www.hal.inserm.fr/inserm-00782581}

Submitted on 30 Jan 2013

HAL is a multi-disciplinary open access archive for the deposit and dissemination of scientific research documents, whether they are published or not. The documents may come from teaching and research institutions in France or abroad, or from public or private research centers.
L'archive ouverte pluridisciplinaire HAL, est destinée au dépôt et à la diffusion de documents scientifiques de niveau recherche, publiés ou non, émanant des établissements d'enseignement et de recherche français ou étrangers, des laboratoires publics ou privés. 


\section{Steroid and nonsteroidal anti-inflammatory drugs, cognitive decline, and dementia}

Marie-Laure Ancelin, PhD. ${ }^{\mathrm{a}, \mathrm{b}, \S,{ }^{*}}$, Isabelle Carrière, $\mathrm{PhD} .{ }^{\mathrm{a}, \mathrm{b}, \S}$, Catherine Helmer, $\mathrm{PhD} .^{\mathrm{c}}$, Olivier Rouaud, MD ${ }^{\mathrm{d}}$, Florence Pasquier, $\mathrm{MD}^{\mathrm{e}}$, Claudine Berr, PhD. ${ }^{\mathrm{a}, \mathrm{b}}$, Isabelle Chaudieu, PhD., ${ }^{\mathrm{a}, \mathrm{b}}$, Karen Ritchie, PhD., ${ }^{\mathrm{a}, \mathrm{b}, \mathrm{f}}$.

${ }^{a}$ Inserm, U1061, Montpellier, F-34093 France

${ }^{\mathrm{b}}$ Université Montpellier 1, U1061, Montpellier, France

${ }^{\mathrm{c}}$ Inserm, U897, Université Bordeaux 2, Bordeaux, France

${ }^{\mathrm{d}}$ Centre Mémoire Ressources et Recherche, Centre Hospitalier Universitaire, Dijon, France

${ }^{\mathrm{e}}$ Department of Neurology, Centre Hospitalier Universitaire, Lille, France

${ }^{\mathrm{f}}$ Faculty of Medicine, Imperial College, London, W12 0NN, U.K.

*Corresponding author at: Inserm U1061, Hopital La Colombiere, 39, avenue C. Flahault, BP 34493, 34093 Montpellier Cedex 5, France

E-mail address: marie-laure.ancelin@inserm.fr (M.L. Ancelin)

Tel: +33 499614 562; Fax: +33 499614579

$\S$ Joint first authors

marie-laure.ancelin@inserm.fr (M.L.A.); isabelle.carriere@inserm.fr (I.C.); catherine.helmer@isped.u-bordeaux2.fr (C.H.); olivier.rouaud@ chu-dijon.fr (O.R.); florence.pasquier@chru-lille.fr (F.P.); claudine.berr@inserm.fr (C.B.); isabelle.chaudieu@inserm.fr (I.Ch.); karen.ritchie@inserm.fr (K.R.) 


\begin{abstract}
The aim of this study was to evaluate the effects of anti-inflammatory intake on cognitive function in 7234 community-dwelling elderly persons. Cognitive performance, clinical diagnosis of dementia, and anti-inflammatory use were evaluated at baseline, and 2, 4, and 7 years later. Multivariate logistic regression analyses were adjusted for sociodemographic, behavioral, physical and mental health variables and genetic vulnerability (APOE 4 ). Elderly women taking inhaled corticosteroids were at increased risk for cognitive decline over 7 years in executive functioning $(\mathrm{OR}=1.76,95 \% \mathrm{CI}=1.14-2.71, \mathrm{p}=0.04)$; the effect being increased after continuous use $(\mathrm{OR}=3.15,95 \% \mathrm{CI}=1.29-7.68, \mathrm{p}=0.01)$ and not found after discontinuation of treatment. In men, no significant associations were observed. Corticosteroid use was not significantly associated with an increase risk of incident dementia over 7 years. Nonsteroidal antiinflammatory drug use was not significantly associated with either dementia incidence or cognitive decline in both sexes. The association may be related to hypothalamic-pituitary-adrenal corticotropic axis dysfunctioning rather than a direct anti-inflammatory mechanism. Long term use of inhaled corticosteroids may constitute a form of reversible cognitive disorder in elderly women. Physicians should check this possibility before assuming neurodegenerative changes.
\end{abstract}

Key-words: Corticosteroids; Nonsteroidal anti-inflammatory drugs; Cognitive aging;

Alzheimer's disease; Elderly; Apolipoprotein E; Prospective cohort. 


\section{Introduction}

In the absence of effective treatment for neuro-degenerative disorders, research has focused on the identification of modifiable risk factors to delay cognitive decline and prolong autonomy (Ritchie et al., 2010). There is some evidence that corticosteroids (CS) could be associated with reversible cognitive dysfunction.; both experimental and epidemiological research showing that dysregulation of the hypothalamic-pituitary-adrenal (HPA) corticotropic axis, a major component of the stress response system, may lead to, or accelerate hippocampal impairment (Belanoff et al., 2001; Conrad and Bimonte-Nelson, 2010; Lupien et al., 2007). This may be especially important in the ageing brain, more vulnerable to stress effects and subject to decrements in cognitive performance due to multiple causes.

Several studies in the elderly have demonstrated a potentially reversible link between elevated endogenous cortisol levels and decline in memory and frontal-executive abilities (Greendale et al., 2000; O'Hara et al., 2007; Seeman et al., 1997; Li et al., 2006; Beluche et al., 2010; Egeland et al., 2005) and dementia (Umegaki et al., 2000; Rasmuson et al., 2002; Csernansky et al., 2006). Associations between short-term CS administration and cognitive impairment have been reported in small experimental and clinical studies in adults (Wolkowitz et al., 2009; Newcomer et al., 1999; Kirschbaum et al., 1996; Lupien et al., 2007; Young et al., 1999; de Quervain et al., 2003; Keenan et al., 1996). The effect of chronic CS administration has, however, never been examined in elderly populations who have high rates of both prescribed and over the counter drug use (Hilmer et al., 2007).

Previous studies have failed to take into account the potential confounding effects on cognitive decline of pathologies associated with CS use, e.g. chronic pain and respiratory disorders, or the impact of CS administration mode, oral administration being generally associated with slower absorption and lower biologically active circulating metabolites than inhaled CS. Surprisingly, genetic vulnerability has also not been considered despite a possible interactive effect between cortisol levels and apolipoproteinE $\varepsilon 4$ allele (APOE $\varepsilon 4$ ) (Lee et al., 
2008). Finally, gender differences have not been examined although they have been reported in relation to both stress response and association between cortisol levels and cognitive decline and neural activity (Otte et al., 2005; Sauro et al., 2003; Seeman et al., 1997; Wang et al., 2007; Beluche et al., 2010) as well as in risk profiles for cognitive impairment and progression to dementia (Artero et al., 2008).

Thus, while there is accumulating evidence to suggest that CS treatment may increase risk of cognitive decline and dementia in the elderly, this hypothesis remains to be tested within a large study able to take into account multiple competing causes of cognitive decline. This prospective study aims to examine the relationship between CS use and cognitive decline and dementia onset in community-dwelling elderly taking into account gender, genetic vulnerability, and reasons for CS use. The cognitive effects of other nonsteroidal anti-inflammatory drugs (NSAID) were also examined.

\section{Methods}

\subsection{Study population}

Subjects were recruited as part of a multi-site cohort study of community-dwelling persons aged 65 years and over from the electoral rolls of three French cities between 1999 and 2001 (The 3C Study Group, 2003). The study protocol was approved by the Ethical Committee of the University-Hospital of Bicêtre (France). Written informed consent was obtained from each participant. Participants were administered standardized questionnaires by trained staff and underwent clinical examinations at baseline and at each 2, 4, and 7year follow-up. Of the 9080 dementia-free participants included, 629 died having only one cognitive evaluation at baseline, 704 were alive at the end of the follow-up but did not have repeated cognitive testing, and 513 had missing data for at least one adjustment variable. The present analyses were conducted on 7234 subjects. The mean (SD) age was 73.6 (5.3) for men and 73.8 (5.2) for women. The average follow-up (median, IQR) was 6.7 (3.8-7.2) years. Subjects not included in the analysis 
were significantly older, with lower education levels, and worse physical and mental health, lower baseline cognitive scores, and were more frequently CS users.

\subsection{Cognitive measures and dementia}

The Isaacs Set Test (Isaacs and Kennie, 1973) provided a measure of verbal fluency or semantic access. The Benton Visual Retention Test (Benton, 1965) assessed visual memory and the Trail Making Tests (TMT) A and B psychomotor speed and executive function respectively (Reitan, 1965). The Mini Mental State Examination (MMSE) was used as a global measure of cognitive function (Folstein et al., 1975). All tests were administered at baseline, and waves 1, 2, and 3 of the follow-up, except the TMT which was not given in wave1. Consequently, analyses relating to these tasks involved only 6085 participants.

A preliminary diagnosis and classification of dementia at each follow-up examination was made by the study clinical investigators according to DSM-IV revised criteria (American Psychiatric Association, 1994) and independently validated by a national panel of neurologists (The 3C Study Group, 2003). The onset of dementia was the date of the follow-up interview when dementia was diagnosed.

\subsection{Corticosteroid and NSAID use}

All prescription and over-the-counter drugs used more than once a week over the preceding month were recorded in a standardized interview. Medical prescriptions and the medications themselves were checked by the interviewer. Oral and inhaled but not topical applications were considered in this analysis.

\subsection{Socio-demographic and clinical variables}

The standardized interview included questions on socio-demographic and lifestyle characteristics with evaluation of hypertension, hypercholesterolemia, and diabetes. Fasting 
blood samples were taken at baseline for lipid and glucose levels and APOE\&4 genotyping (Ritchie et al., 2007). History of ischemic pathologies (stroke, angina pectoris, myocardial infarction and cardio-vascular surgery) was established according to standardized questions. Chronic bronchitis (daily sputum or mucus production or cough for at least 3 consecutive months/year), other chronic respiratory disorders including wheezing, tachypnea, and asthma attacks (over the last 12months) were self-reported as well as chronic/regular joint or back pain. Depressive symptomatology was assessed by the Center for Epidemiological Studies-Depression Scale (CES-D) (Radloff, 1977) with a 16 cut-off point.

\subsection{Statistical analyses}

We used logistic regression analyses to determine whether baseline anti-inflammatory use was associated with odds of cognitive decline. Men and women were examined in separate analyses as they differed in both anti-inflammatory drug use and profiles of cognitive ability. The Chi2 test was used to identify gender-related differences. After gender stratification, OR were adjusted for centre, age, educational level, and baseline cognitive performance (minimally adjusted model). Multivariate adjusted logistic regression further included covariates associated with cognitive decline (at $\mathrm{p}<0.15$ ); depression, diabetes, hypercholesterolemia, caffeine, smoking, APOE\&4, ischemic pathologies, chronic joint or back pain, bronchitis, asthma and other chronic respiratory disorders. Due to the skewed distribution of cognitive scores, a substantial decline in cognitive function over follow-up was defined as the lowest quintile of the difference between either follow-up visit and baseline score except for response time recorded for the TMT, for which the highest quintile of the difference was considered (Ritchie et al., 2007). We also used random-effect models to analyze the association between CS use and 7-year change on cognitive scores taken as continuous variables. In order to normalize the distribution, variables were transformed using $(15-\text { Benton })^{1 / 2},(30-\mathrm{MMSE})^{1 / 2}$ and $\log$ TMT (Jacqmin-Gadda et al., 1997). Each model included time, CS, time/CS interaction and covariates. The term CS 
represents the cross-sectional association between CS and baseline cognitive score. The term time indicates the linear evolution per year on the cognitive test. The term for interaction represents the additional annual modification on the selected cognitive tests for CS use. A Cox model with delayed entry was used in the analysis of dementia incidence taking age as the basic time scale and birth as the time origin (Commenges et al., 1998). This analysis was undertaken on 7486 subjects without missing data for baseline adjustment variables but with possibly missing repeated cognitive testing. Analyses were carried out using SAS software (version 9.1).

\section{Results}

\subsection{Subject characteristics}

Within this elderly community-dwelling sample, 352 of the 7234 subjects (4.9\%) were taking CS at baseline, of whom $112(1.6 \%)$ used oral and 240 (3.3\%) inhaled preparations. Oral CS principally consisted of prednisone (16.2\% of CS users), prednisolone (4.9\%), methylprednisolone (2.8\%) and hydrocortisone (2.3\%). The main inhaled CS were beclometasone (27.4\%), budesonide (20.5\%), fluticasone (12.1\%) and triamcinolone (5.9\%) (table e-1). Fifteen subjects were taking simultaneously inhaled and oral CS. Both oral and inhaled prednisolone and triamcinolone were used, the former being predominantly by oral administration and the latter inhaled. Women used more frequently oral (1.7\%) and less frequently inhaled (3.0\%) CS than men ( $1.3 \%$ and $3.9 \%$, respectively, $\mathrm{p}=0.04)$. Men and women were found to significantly differ on all other characteristics at baseline except APO 4 . A higher proportion of women showed low scores on the MMSE, Benton, and TMTA and TMTB but not on the Isaacs test (data not shown).

For both men and women, CS use was higher in subjects with chronic joint or back pain and respiratory disorders ( $\mathrm{p}<0.0001)$ (Table 1). Men with lower education level and low MMSE and Isaacs scores at baseline were more frequent CS users ( $p<0.05)$, whereas women using CS tended to have lower performance on TMTB $(\mathrm{p}=0.06)$. 


\subsection{CS use and cognitive decline}

Logistic regression analysis adjusted for age, center, education level and baseline cognitive performance indicated that women reporting use of inhaled but not oral CS at baseline showed greater decline over 7years on the TMTB $(\mathrm{OR}=1.65,95 \% \mathrm{CI}=1.10-2.47)$ (Table 2$)$. The association persisted in the complete model further adjusted for other confounders including pathologies associated with CS prescription (chronic pain and respiratory disorders, etc.) $(\mathrm{OR}=1.76,95 \% \mathrm{CI}=1.14-2.71)$. No significant interactions were found for decline on TMTB in women between CS use and age $(\mathrm{p}=0.12)$ or APOE $(\mathrm{p}=0.38)$. No significant effect was observed in men regardless of the cognitive domain. Performing multivariate-adjusted random-effect linear models with the cognition score as the continuous variable led to the same results, the only significant association being found between CS use and performance on the TMTB in women (interaction between time and inhaled CS p $=0.003$, slope of $\log (\mathrm{TMTB})$ increased by 0.008 compared to no CS use). Similar findings were observed when executive function was assessed using score differences such as time on TMTB minus time on TMTA (data not shown).

\subsection{Cognitive decline according to the pattern of CS use during follow-up}

Of the 3736 women with a TMT evaluation, 3171 (84.9\%) did not report CS use (oral or inhaled) at baseline and during the 7-year follow-up, 38 (1.0\%) reported inhaled CS use only at baseline or after the first 2-year follow-up, but not at either 4- or 7-year follow-up (“discontinuing" group), and $22(0.5 \%)$ reported inhaled CS use both at baseline and at least at the 2- and 4-year examination (3 consecutive examinations, "continuing" group). Other subjects having reported inhaled CS use intermittently during the follow-up or having taken oral CS at baseline or during the follow-up $(n=505)$ were not considered in the following analyses.

Compared to women who had never used CS, women having continuously used inhaled CS were at higher risk of cognitive decline on the TMTB in fully-adjusted models $(\mathrm{OR}=3.15$, 
95\% CI=1.29-7.68, $\mathrm{p}=0.01$ ) (Table 3). The association was not significant for women in the “discontinuous" group $(\mathrm{OR}=1.41,95 \% \mathrm{CI}=0.69-2.89, \mathrm{p}=0.35)$.

\subsection{NSAID and cognitive decline}

A total of 180 men (6.4\%) and 452 women (10.3\%) were taking NSAID at baseline. Thirty-four (0.5\%) were taking both NSAID and CS. NSAID principally consisted of diacerein (23.1\% of users), diclofenac (14.5\%), piroxicam (14.2\%), ketoprofen (9.9\%), and ibuprofen $(8.6 \%)$ and $6.8 \%$ were taking coxibs (table e-2). There was no significant association between NSAID use at baseline and cognitive decline in men and women (Table 4). Examining cognitive decline according to the pattern of NSAID use during follow-up, we only observed a nonsignificant association with an increased risk of decline on the Isaacs' task in the 100 women having used NSAID continuously [multi-adjusted $(\mathrm{OR})=1.50,95 \% \mathrm{CI}=0.96-2.35, \mathrm{p}=0.08]$.

\subsection{Dementia incidence}

Within the 7486 subjects included in the analysis 527 incident cases were diagnosed during the 7-year follow-up, of whom 360 had Alzheimer's disease (AD). Adjusted Cox models failed to find a significant association between the incidence of dementia or AD and CS or NSAID use at baseline (Table 5).

\section{Discussion}

\subsection{CS use and cognitive decline}

Our results indicate a 1.8-fold increased risk of decline in a cognitive task sensitive to alterations in psychomotor speed and frontal executive functioning in women only. The same results were obtained in the minimally and the fully adjusted model, which was further adjusted for the pathologies associated with CS treatment (such as chronic pain and respiratory disorders) (Belanoff et al., 2001) and using two different models (logistic regression and random-effect 
models). This underlines the consistency of these associations, in spite of an eventual risk of over-adjustment and suggests that the cognitive decline was more likely related to the CS themselves rather than the underlying burden of illness, making unlikely an eventual prescription bias. This is also supported by the observation that risk of cognitive decline nearly doubled $(\mathrm{OR}=3.2, \mathrm{p}=0.01)$ with longer treatment and continuous use, and was non-significant after discontinuation.

Systemic toxicity is known to be a major concern with long-term use of high-dose glucocorticoids. In our study, the deleterious effect on cognitive function was only observed for inhaled CS. This may be linked to differences in the active substances and/or pharmacodynamic properties related to administration mode; oral administration being generally associated with slower absorption/distribution, higher metabolism due to hepatic first-pass effect, and lower biologically active circulating metabolites. Adrenal insufficiency and Cushing's syndrome have also been reported in patients treated with inhaled CS (Molimard et al., 2008). In our study, however, the small number of subjects taking CS using either mode did not allow us to examine the effect of administration method. We also did not have any information on patient conformity to prescription; inhaled CS being more likely to be over-dosed.

Only a few small experimental studies in healthy young or adult participants have examined the link between acute or short-term glucocorticoid administration and cognitive impairment. Cognitive assessment has principally focused on changes in declarative memory consistent with deficiencies in hippocampus-dependent activity, although recent studies have also noted impairments in prefrontal cortex processing (Wolkowitz et al., 2009; Lupien et al., 2007; Franz et al., 2011); both structures having a relatively high density of gluco- and mineralocorticoid receptors. These associations may be transient and dose-dependent (Newcomer et al., 1999; Kirschbaum et al., 1996; Young et al., 1999; de Quervain et al., 2003; Keenan et al., 1996). A lower sensitivity of verbal memory skills compared to other cognitive functions has been reported in young adults after acute CS administration (Lupien et al., 2007) and recently in 
older adults, in a large study using an extensive cognitive battery; high cortisol levels being specifically associated with poor frontal-executive functions (Franz et al., 2011). No such studies have been performed in the elderly.

In our study poor performance is only seen on the TMTB and not on the TMTA trial (the A trial not involving the cognitive switching task)-and similar results were observed when executive function was assessed using score differences. This thus suggests that executive performance is affected rather than psychomotor speed. Neuropsychological tests requiring intact prefrontal cortical activity such as the TMTB may thus be especially vulnerable to chronic inhaled CS use in elderly women. A "two-factor model of brain aging" which posits that endocrine-related aging, like normal aging, may primarily involve loss of frontal-striatal circuits with associated executive function changes, whereas pathological cognitive aging (e.g. AD) is more strongly associated with hippocampal abnormalities appears to support our observations but remains speculative (Buckner, 2004; Hedden and Gabrieli, 2004; Franz et al., 2011).

\subsection{Gender specificity}

We did not observe a significant association between CS use and cognitive decline for men. This could be due to pharmacodynamic or metabolism differences. In a meta-analysis, Otte et al. reported a three-fold stronger effect of age on cortisol response in women than in men (Otte et al., 2005). A gender difference in biological response to stress both at a functional and structural level may also be possible (Kudielka et al., 2004; Kumsta et al., 2007; Pruessner et al., 2010). Overall, specific cognitive functions may be affected by cumulative exposure to chronic stress via glucocorticoids released from the HPA axis, but also from gonadal steroids released from the hypothalamic-pituitary-gonadal axis (notably estrogens and testosterone which have distinct cognitive effects in women and men) (Conrad and Bimonte-Nelson, 2010). Interestingly, hypercortisolism and steroid dementia syndrome previously reported in adult patients after glucocorticoid intake at high doses and for extended periods, show some pathophysiological 
similarities with the cognitive features observed in this study, including durable executive dysfunction, higher incidence in females, dose dependency, and reversibility (Egeland et al., 2005; Wolkowitz et al., 2007; Lewis and Smith, 1983; Sacks and Shulman, 2005; Wolkowitz et al., 2009).

\subsection{CS use and dementia}

We observed no significant association between CS use at baseline and risk of developing dementia over 7-years. To date only one randomized controlled trial has examined the effect of 1-year prednisone treatment on cognitive decline in Alzheimer's patients (Aisen et al., 2000) showing no significant difference between CS and placebo treated patients. CS dose and exposure duration could also be evoked, but the small number of demented subjects taking CS $(n=28)$ have precluded exploration of this possibility.

\subsection{NSAID use, cognitive decline, and dementia}

We did not observe any significant associations between NSAID intake at baseline and cognitive decline and dementia over 7-years. In observational studies, exposure to NSAID were possibly associated with decreased risk for cognitive decline and $\mathrm{AD}$, depending on class and dose, longer duration or younger age at intake, and APOع4 vulnerability (Szekely et al., 2004; Szekely et al., 2008; Vlad et al., 2008; de Craen et al., 2005; Gorelick, 2010; Szekely and Zandi, 2010). Conversely, the three randomized controlled trials performed using rofecoxib, celecoxib and naproxen, suggested an increased risk in $\mathrm{AD}$ and no consistent association or worsening of cognitive function with naproxen (in global summary scores and verbal fluency) (Thal et al., 2005; Lyketsos et al., 2007; Martin et al., 2008).

Inflammatory processes are complex and may have either reparative or detrimental effects on neurons (Wyss-Coray and Mucke, 2002). In our study, neither CS nor NSAID appeared to be beneficial for cognitive dysfunction or dementia, which does not support the hypothesis that 
inhibiting inflammation can reduce neurodegenerative processes in the elderly. The different patterns of cognitive change observed in our study between CS and NSAID suggests that deleterious CS effects on executive function may be more likely related to glucocorticoid and HPA axis functioning rather than an anti-inflammatory effect.

\subsection{Limitations and strengths}

A limitation of our study was the use of some self-reported covariates with eventual subsequent recall bias. Bias could also have been introduced through the exclusion of participants, those lost to follow-up being more likely to have dementia, to be older, and thus with worse physical and mental health, and using CS more frequently. This may limit the generalizability of our results, and associations may have thus been underestimated. We did not consider treatment compliance, which may have caused classification bias. Since we did not have data on precise duration of medication use, we could not definitively address the question of whether prolonged use could precipitate non-reversible dementia. Finally, since multiple analyses have been performed we cannot exclude that some observed associations were due to a chance finding.

The strengths of this study relate principally to its prospective, community-based design, large size and extensive information obtained on clinical status. CS and NSAID use was verified by examining prescriptions and medications, thus minimizing exposure misclassification and with the advantage, compared to reimbursement data, of including self-medication (Noize et al., 2009). Finally, we have taken into account a wide range of competing causes of cognitive dysfunction in the elderly, by controlling for socio-demographic, genetic, health and lifestyle covariates, thus limiting any potential confounding including prescription bias.

In conclusion, findings from this study suggest that inhaled CS use is associated with poorer executive performance in elderly women; the principal clinical and functional implication 
being that medical practitioners should take chronic CS use into account before making a differential diagnosis of early neurodegenerative disorder. 


\section{Disclosure statement}

Drs Ancelin, Carrière, Helmer, Rouaud, Pasquier, Berr, and Chaudieu report no disclosures. Dr. Ritchie serves on scientific advisory boards for the Biomedical Research Centre, King's College London, and London and MRC Strategic Steering Committee (Longitudinal Health and Aging Research Unit).

\section{Acknowledgements}

The 3C Study is conducted under a partnership agreement between Inserm, the Victor Segalen - Bordeaux II University and Sanofi-Synthélabo. The Fondation pour la Recherche Médicale funded the preparation and first phase of the study. The 3C-Study is also supported by the Caisse Nationale Maladie des Travailleurs Salariés, Direction Générale de la Santé, MGEN, Institut de la Longévité, Agence Française de Sécurité Sanitaire des Produits de Santé, the Regional Governments of Aquitaine, Bourgogne and Languedoc-Roussillon and, the Fondation de France, the Ministry of Research-Inserm Programme "Cohorts and collection of biological material”. The Lille Génopôle received an unconditional grant from Eisai. Part of this project is financed by two grants from the Agence Nationale de la Recherche (projects 07 LVIE 004 and 06-PNRA-005). We thank the Génopôle of Lille, the Laboratories of Biochemistry of the University Hospitals of Dijon and Montpellier, the Town Council of Dijon and the Conseil Général of Côte d'Or. Neither funding source provided scientific input to the study.

\section{Appendix A. Supplementary data}

Two eTables listing the frequency of use of CS and NSAID among study participants. 


\section{References}

Aisen, P.S., Davis, K.L., Berg, J.D., Schafer, K., Campbell, K., Thomas, R.G., Weiner, M.F., Farlow, M.R., Sano, M., Grundman, M., Thal, L.J., 2000. A randomized controlled trial of prednisone in Alzheimer's disease. Alzheimer's Disease Cooperative Study. Neurology 54, 588-593.

American Psychiatric Association, 1994. Diagnostic and Statistical Manual of Mental Disorders (DSM-IV). American Psychiatric Association, Washington, DC.

Artero, S., Ancelin, M.L., Portet, F., Dupuy, A., Berr, C., Dartigues, J.F., Tzourio, C., Rouaud, O., Poncet, M., Pasquier, F., Auriacombe, S., Touchon, J., Ritchie, K., 2008. Risk profiles for mild cognitive impairment and progression to dementia are gender specific. J Neurol Neurosurg Psychiatry 79, 979-984.

Belanoff, J.K., Gross, K., Yager, A., Schatzberg, A.F., 2001. Corticosteroids and cognition. J Psychiatr Res 35, 127-145.

Beluche, I., Carriere, I., Ritchie, K., Ancelin, M.L., 2010. A prospective study of diurnal cortisol and cognitive function in community-dwelling elderly people. Psychol Med 40, 10391049.

Benton, A. Manuel pour l'application du test de rétention visuelle. Applications cliniques et expérimentales. Paris: Centre de Psychologie Appliquée; 1965.

Buckner, R.L., 2004. Memory and executive function in aging and AD: multiple factors that cause decline and reserve factors that compensate. Neuron 44, 195-208.

Commenges, D., Letenneur, L., Joly, P., Alioum, A., Dartigues, J.F., 1998. Modelling agespecific risk: application to dementia. Stat Med 17, 1973-1988.

Conrad, C.D., Bimonte-Nelson, H.A., 2010. Impact of the hypothalamic-pituitaryadrenal/gonadal axes on trajectory of age-related cognitive decline. Prog Brain Res 182, $31-76$. 
Csernansky, J.G., Dong, H., Fagan, A.M., Wang, L., Xiong, C., Holtzman, D.M., Morris, J.C., 2006. Plasma cortisol and progression of dementia in subjects with Alzheimer-type dementia. Am J Psychiatry 163, 2164-2169.

de Craen, A.J., Gussekloo, J., Vrijsen, B., Westendorp, R.G., 2005. Meta-analysis of nonsteroidal antiinflammatory drug use and risk of dementia. Am J Epidemiol 161, 114120.

de Quervain, D.J., Henke, K., Aerni, A., Treyer, V., McGaugh, J.L., Berthold, T., Nitsch, R.M., Buck, A., Roozendaal, B., Hock, C., 2003. Glucocorticoid-induced impairment of declarative memory retrieval is associated with reduced blood flow in the medial temporal lobe. Eur J Neurosci 17, 1296-1302.

Egeland, J., Lund, A., Landro, N.I., Rund, B.R., Sundet, K., Asbjornsen, A., Mjellem, N., Roness, A., Stordal, K.I., 2005. Cortisol level predicts executive and memory function in depression, symptom level predicts psychomotor speed. Acta Psychiatr Scand 112, 434441.

Folstein, M.F., Folstein, S.E., McHugh, P.R., 1975. "Mini-mental state". A practical method for grading the cognitive state of patients for the clinician. J Psychiatr Res 12, 189-198.

Franz, C.E., O'Brien, R.C., Hauger, R.L., Mendoza, S.P., Panizzon, M.S., Prom-Wormley, E., Eaves, L.J., Jacobson, K., Lyons, M.J., Lupien, S., Hellhammer, D., Xian, H., Kremen, W.S., 2011. Cross-sectional and 35-year longitudinal assessment of salivary cortisol and cognitive functioning: The Vietnam Era Twin Study of Aging. Psychoneuroendocrinology doi:10.1016/j.psyneuen.2011.01.002.

Gorelick, P.B., 2010. Role of inflammation in cognitive impairment: results of observational epidemiological studies and clinical trials. Ann N Y Acad Sci 1207, 155-162.

Greendale, G.A., Kritz-Silverstein, D., Seeman, T., Barrett-Connor, E., 2000. Higher basal cortisol predicts verbal memory loss in postmenopausal women: Rancho Bernardo Study. J Am Geriatr Soc 48, 1655-1658. 
Hedden, T., Gabrieli, J.D., 2004. Insights into the ageing mind: a view from cognitive neuroscience. Nat Rev Neurosci 5, 87-96.

Hilmer, S.N., McLachlan, A.J., Le Couteur, D.G., 2007. Clinical pharmacology in the geriatric patient. Fundam Clin Pharmacol 21, 217-230.

Isaacs, B., Kennie, A.T., 1973. The Set test as an aid to the detection of dementia in old people. Br J Psychiatry 123, 467-470.

Jacqmin-Gadda, H., Fabrigoule, C., Commenges, D., Dartigues, J.F., 1997. A 5-year longitudinal study of the Mini-Mental State Examination in normal aging. Am J Epidemiol 145, 498506.

Keenan, P.A., Jacobson, M.W., Soleymani, R.M., Mayes, M.D., Stress, M.E., Yaldoo, D.T., 1996. The effect on memory of chronic prednisone treatment in patients with systemic disease. Neurology 47, 1396-1402.

Kirschbaum, C., Wolf, O.T., May, M., Wippich, W., Hellhammer, D.H., 1996. Stress- and treatment-induced elevations of cortisol levels associated with impaired declarative memory in healthy adults. Life Sci 58, 1475-1483.

Kudielka, B.M., Buske-Kirschbaum, A., Hellhammer, D.H., Kirschbaum, C., 2004. HPA axis responses to laboratory psychosocial stress in healthy elderly adults, younger adults, and children: impact of age and gender. Psychoneuroendocrinology 29, 83-98.

Kumsta, R., Entringer, S., Koper, J.W., van Rossum, E.F., Hellhammer, D.H., Wust, S., 2007. Sex specific associations between common glucocorticoid receptor gene variants and hypothalamus-pituitary-adrenal axis responses to psychosocial stress. Biol Psychiatry 62, 863-869.

Lee, B.K., Glass, T.A., Wand, G.S., McAtee, M.J., Bandeen-Roche, K., Bolla, K.I., Schwartz, B.S., 2008. Apolipoprotein E Genotype, Cortisol, and Cognitive Function in CommunityDwelling Older Adults. Am J Psychiatry 165, 1456-1464. 
Lewis, D.A., Smith, R.E., 1983. Steroid-induced psychiatric syndromes. A report of 14 cases and a review of the literature. J Affect Disord 5, 319-332.

Li, G., Cherrier, M.M., Tsuang, D.W., Petrie, E.C., Colasurdo, E.A., Craft, S., Schellenberg, G.D., Peskind, E.R., Raskind, M.A., Wilkinson, C.W., 2006. Salivary cortisol and memory function in human aging. Neurobiol Aging 27, 1705-1714.

Lupien, S.J., Maheu, F., Tu, M., Fiocco, A., Schramek, T.E., 2007. The effects of stress and stress hormones on human cognition: Implications for the field of brain and cognition. Brain Cogn 65, 209-237.

Lyketsos, C.G., Breitner, J.C., Green, R.C., Martin, B.K., Meinert, C., Piantadosi, S., Sabbagh, M., 2007. Naproxen and celecoxib do not prevent AD in early results from a randomized controlled trial. Neurology 68, 1800-1808.

Martin, B.K., Szekely, C., Brandt, J., Piantadosi, S., Breitner, J.C., Craft, S., Evans, D., Green, R., Mullan, M., 2008. Cognitive function over time in the Alzheimer's Disease Antiinflammatory Prevention Trial (ADAPT): results of a randomized, controlled trial of naproxen and celecoxib. Arch Neurol 65, 896-905.

Molimard, M., Girodet, P.O., Pollet, C., Fourrier-Reglat, A., Daveluy, A., Haramburu, F., Fayon, M., Tabarin, A., 2008. Inhaled corticosteroids and adrenal insufficiency: prevalence and clinical presentation. Drug Saf 31, 769-774.

Newcomer, J.W., Selke, G., Melson, A.K., Hershey, T., Craft, S., Richards, K., Alderson, A.L., 1999. Decreased memory performance in healthy humans induced by stress-level cortisol treatment. Arch Gen Psychiatry 56, 527-533.

Noize, P., Bazin, F., Dufouil, C., Lechevallier-Michel, N., Ancelin, M.L., Dartigues, J.F., Tzourio, C., Moore, N., Fourrier-Reglat, A., 2009. Comparison of health insurance claims and patient interviews in assessing drug use: data from the Three-City (3C) Study. Pharmacoepidemiol Drug Saf 18, 310-319. 
O'Hara, R., Schroder, C.M., Mahadevan, R., Schatzberg, A.F., Lindley, S., Fox, S., Weiner, M., Kraemer, H.C., Noda, A., Lin, X., Gray, H.L., Hallmayer, J.F., 2007. Serotonin transporter polymorphism, memory and hippocampal volume in the elderly: association and interaction with cortisol. Mol Psychiatry 12, 544-555.

Otte, C., Hart, S., Neylan, T.C., Marmar, C.R., Yaffe, K., Mohr, D.C., 2005. A meta-analysis of cortisol response to challenge in human aging: importance of gender.

Psychoneuroendocrinology 30, 80-91.

Pruessner, J.C., Dedovic, K., Pruessner, M., Lord, C., Buss, C., Collins, L., Dagher, A., Lupien, S.J., 2010. Stress regulation in the central nervous system: evidence from structural and functional neuroimaging studies in human populations. Psychoneuroendocrinology 35, $179-191$

Radloff, L., 1977. The CES-D scale: a self-report depression scale for research in the general population. Appl Psychol Measurement 1, 385-401.

Rasmuson, S., Nasman, B., Carlstrom, K., Olsson, T., 2002. Increased levels of adrenocortical and gonadal hormones in mild to moderate Alzheimer's disease. Dement Geriatr Cogn Disord 13, 74-79.

Reitan, R., 1965. Validity of the Trail Making Test as an indicator of organic brain damage. Percept Mot Skills 8, 271-276.

Ritchie, K., Carriere, I., de Mendonca, A., Portet, F., Dartigues, J.F., Rouaud, O., BarbergerGateau, P., Ancelin, M.L., 2007. The neuroprotective effects of caffeine: a prospective population study (the Three City Study). Neurology 69, 536-545.

Ritchie, K., Carriere, I., Ritchie, C.W., Berr, C., Artero, S., Ancelin, M.L., 2010. Designing prevention programs to reduce dementia incidence. A prospective study of modifiable risk factors. Br Med J, on line first, Aug 5, 341:c3885.

Sacks, O., Shulman, M., 2005. Steroid dementia: an overlooked diagnosis? Neurology 64, 707709. 
Sauro, M.D., Jorgensen, R.S., Pedlow, C.T., 2003. Stress, glucocorticoids, and memory: a metaanalytic review. Stress 6, 235-245.

Seeman, T.E., McEwen, B.S., Singer, B.H., Albert, M.S., Rowe, J.W., 1997. Increase in urinary cortisol excretion and memory declines: MacArthur studies of successful aging. J Clin Endocrinol Metab 82, 2458-2465.

Szekely, C.A., Green, R.C., Breitner, J.C., Ostbye, T., Beiser, A.S., Corrada, M.M., Dodge, H.H., Ganguli, M., Kawas, C.H., Kuller, L.H., Psaty, B.M., Resnick, S.M., Wolf, P.A., Zonderman, A.B., Welsh-Bohmer, K.A., Zandi, P.P., 2008. No advantage of A beta 42lowering NSAIDs for prevention of Alzheimer dementia in six pooled cohort studies. Neurology 70, 2291-2298.

Szekely, C.A., Thorne, J.E., Zandi, P.P., Ek, M., Messias, E., Breitner, J.C., Goodman, S.N., 2004. Nonsteroidal anti-inflammatory drugs for the prevention of Alzheimer's disease: a systematic review. Neuroepidemiology 23, 159-169.

Szekely, C.A., Zandi, P.P., 2010. Non-steroidal anti-inflammatory drugs and Alzheimer's disease: the epidemiological evidence. CNS Neurol Disord Drug Targets 9, 132-139. Thal, L.J., Ferris, S.H., Kirby, L., Block, G.A., Lines, C.R., Yuen, E., Assaid, C., Nessly, M.L., Norman, B.A., Baranak, C.C., Reines, S.A., 2005. A randomized, double-blind, study of rofecoxib in patients with mild cognitive impairment. Neuropsychopharmacology 30 , 1204-1215.

The 3C Study Group, 2003. Vascular factors and risk of dementia: Design of the three city study and baseline characteristics of the study population. Neuroepidemiology 22, 316-325.

Umegaki, H., Ikari, H., Nakahata, H., Endo, H., Suzuki, Y., Ogawa, O., Nakamura, A., Yamamoto, T., Iguchi, A., 2000. Plasma cortisol levels in elderly female subjects with Alzheimer's disease: a cross-sectional and longitudinal study. Brain Res 881, 241-243. Vlad, S.C., Miller, D.R., Kowall, N.W., Felson, D.T., 2008. Protective effects of NSAIDs on the development of Alzheimer disease. Neurology 70, 1672-1677. 
Wang, J., Korczykowski, M., Rao, H., Fan, Y., Pluta, J., Gur, R.C., McEwen, B.S., Detre, J.A., 2007. Gender Difference in Neural Response to Psychological Stress. Soc Cogn Affect Neurosci 2, 227-239.

Wolkowitz, O.M., Burke, H., Epel, E.S., Reus, V.I., 2009. Glucocorticoids. Mood, memory, and mechanisms. Ann N Y Acad Sci 1179, 19-40.

Wolkowitz, O.M., Lupien, S.J., Bigler, E.D., 2007. The "steroid dementia syndrome": a possible model of human glucocorticoid neurotoxicity. Neurocase 13, 189-200.

Wyss-Coray, T., Mucke, L., 2002. Inflammation in neurodegenerative disease - a double-edged sword. Neuron 35, 419-432.

Young, A.H., Sahakian, B.J., Robbins, T.W., Cowen, P.J., 1999. The effects of chronic administration of hydrocortisone on cognitive function in normal male volunteers. Psychopharmacology (Berl) 145, 260-266. 
Table 1. Characteristics of the study population as a function of corticosteroid use at baseline

\begin{tabular}{|c|c|c|c|c|c|c|}
\hline \multirow[b]{4}{*}{ Characteristic } & \multicolumn{3}{|l|}{ Men } & \multicolumn{3}{|l|}{ Women } \\
\hline & \multicolumn{3}{|c|}{ CS drugs } & \multicolumn{3}{|l|}{ CS drugs } \\
\hline & $\begin{array}{c}\text { No } \\
(n=2686)\end{array}$ & $\begin{array}{l}\text { Yes } \\
(n=147)\end{array}$ & $p$ & $\begin{array}{l}\text { No } \\
(n=4196)\end{array}$ & $\begin{array}{l}\text { Yes } \\
(n=205)\end{array}$ & \\
\hline & $\%$ & $\%$ & & $\%$ & $\%$ & \\
\hline Age & & & 0.17 & & & 0.30 \\
\hline $65-69$ & 26.3 & 21.8 & & 25.2 & 20.5 & \\
\hline $70-74$ & 35.1 & 31.3 & & 32.5 & 34.1 & \\
\hline $75-80$ & 24.5 & 27.2 & & 28.1 & 32.7 & \\
\hline $80+$ & 14.1 & 19.7 & & 14.2 & 12.7 & \\
\hline Education & & & 0.03 & & & 0.47 \\
\hline 5 years & 21.5 & 24.5 & & 25.4 & 25.4 & \\
\hline 9 years & 30.0 & 38.1 & & 39.9 & 43.4 & \\
\hline 12 years & 19.8 & 11.6 & & 20.8 & 21.0 & \\
\hline $12+$ & 28.7 & 25.8 & & 13.9 & 10.2 & \\
\hline Marital status & & & 0.32 & & & 0.54 \\
\hline Married & 82.6 & 80.8 & & 45.8 & 41.9 & \\
\hline Single or & 7.7 & 11.0 & & 18.9 & 21.0 & \\
\hline divorced & 9.7 & 8.2 & & 35.3 & 37.1 & \\
\hline Widowed & & & & & & \\
\hline $\begin{array}{l}\text { Depressive symptoms } \\
\left(C E S-D \geq 16^{\mathrm{a}}\right)\end{array}$ & 13.4 & 18.4 & 0.09 & 28.3 & 31.2 & 0.37 \\
\hline Ischemic pathologies & 21.8 & 25.9 & 0.25 & 12.2 & 15.6 & 0.14 \\
\hline BMI & & & 0.59 & & & 0.20 \\
\hline Normal & 38.0 & 34.3 & & 53.6 & 50.7 & \\
\hline Overweight & 49.1 & 53.4 & & 33.2 & 31.7 & \\
\hline Obese & 12.8 & 12.3 & & 13.2 & 17.6 & \\
\hline Diabetes $^{c}$ & 12.6 & 15.0 & 0.41 & 6.7 & 10.2 & 0.05 \\
\hline Chronic bronchitis ${ }^{\mathrm{d}}$ & 3.8 & 21.1 & $<0.0001$ & 2.2 & 12.2 & $<0.0001$ \\
\hline Asthma $^{\mathrm{e}}$ & 1.5 & 14.3 & $<0.0001$ & 1.9 & 23.9 & $<0.0001$ \\
\hline Hypertension ${ }^{\mathrm{f}}$ & 59.9 & 60.5 & 0.87 & 53.4 & 59.5 & 0.09 \\
\hline$\underset{\mathrm{g}}{\text { Hypercholesterolemia }}$ & 83.4 & 80.3 & 0.32 & 68.0 & 63.4 & 0.17 \\
\hline Alcohol & & & 0.75 & & & 0.29 \\
\hline 0 & 8.0 & 7.5 & & 26.9 & 31.7 & \\
\hline $1-36 \mathrm{~g} /$ day & 73.2 & 71.2 & & 71.5 & 67.3 & \\
\hline$>36 \mathrm{~g} /$ day & 18.8 & 21.2 & & 1.6 & 1.0 & \\
\hline Smoking & & & 0.14 & & & 0.27 \\
\hline Never & 30.5 & 23.8 & & 81.4 & 79.0 & \\
\hline Former & 61.3 & 69.4 & & 14.9 & 18.6 & \\
\hline Current & 8.2 & 6.8 & & 3.7 & 2.4 & \\
\hline NSAID use & 6.2 & 9.5 & 0.11 & 10.3 & 9.8 & 0.80 \\
\hline $\begin{array}{l}\text { Self-report chronic } \\
\text { joint or back pain }\end{array}$ & 9.6 & 20.4 & $<0.0001$ & 16.6 & 26.3 & 0.0003 \\
\hline
\end{tabular}




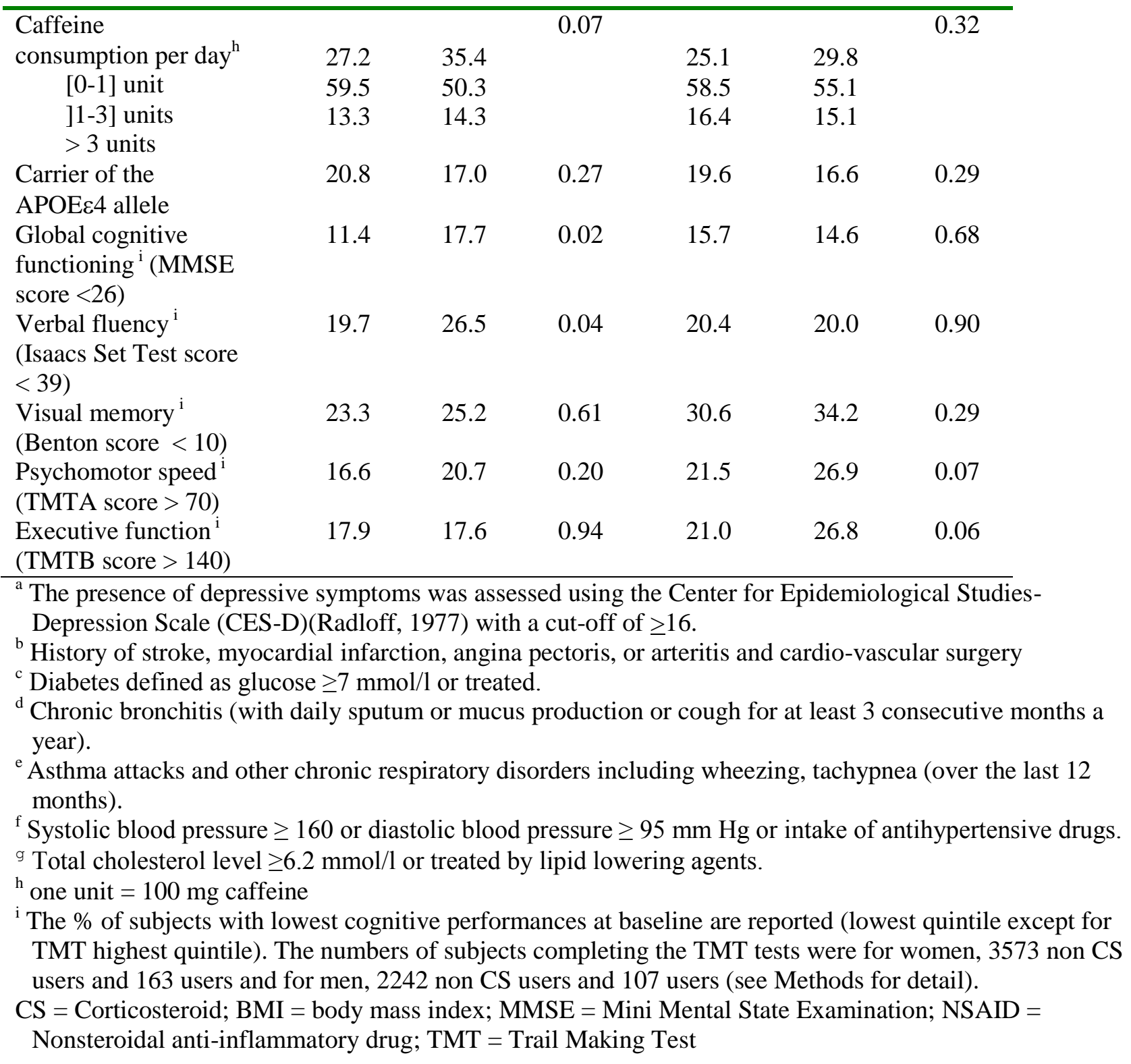


Table 2. Baseline corticosteroid (CS) use and cognitive decline ${ }^{\mathrm{a}}$ over the 7-year follow-up period

\begin{tabular}{|c|c|c|c|c|}
\hline & \multicolumn{2}{|l|}{$\operatorname{MEN}(n=2833)^{b}$} & \multicolumn{2}{|c|}{ WOMEN $(n=4401)^{b}$} \\
\hline & OR $[95 \% \mathrm{CI}]^{\mathrm{b}}$ & Global $p$-value & OR $[95 \% \mathrm{CI}]^{\mathrm{b}}$ & Global $p$-value \\
\hline \multicolumn{5}{|c|}{ Minimally adjusted $^{c}$} \\
\hline \multicolumn{5}{|l|}{$\Delta \mathbf{M M S E} \leq-2$} \\
\hline Oral CS & $1.18[0.60 ; 2.33]$ & 0.62 & $1.05[0.65 ; 1.70]$ & 0.15 \\
\hline Inhaled CS & $1.20[0.80 ; 1.79]$ & & $0.68[0.47 ; 1.01]$ & \\
\hline \multicolumn{5}{|l|}{$\Delta$ Benton $\leq-2$} \\
\hline Oral CS & $1.08[0.54 ; 2.18]$ & \multirow{2}{*}{0.55} & $1.19[0.72 ; 1.97]$ & \multirow{2}{*}{0.36} \\
\hline Inhaled CS & $0.79[0.52 ; 1.21]$ & & $1.29[0.87 ; 1.91]$ & \\
\hline \multicolumn{5}{|l|}{$\Delta$ Isaacs $\leq-6$} \\
\hline Oral CS & $1.42[0.70 ; 2.87]$ & \multirow{2}{*}{0.61} & $1.14[0.70 ; 1.87]$ & \multirow{2}{*}{0.34} \\
\hline Inhaled CS & $1.05[0.69 ; 1.60]$ & & $0.76[0.51 ; 1.13]$ & \\
\hline \multicolumn{5}{|l|}{$\Delta \mathbf{T M T A} \geq 15$} \\
\hline Oral CS & $1.17[0.54 ; 2.57]$ & \multirow{2}{*}{0.87} & $1.03[0.56 ; 1.90]$ & \multirow{2}{*}{0.58} \\
\hline Inhaled CS & $1.09[0.65 ; 1.83]$ & & $0.78[0.49 ; 1.25]$ & \\
\hline \multicolumn{5}{|l|}{$\Delta \mathbf{T M T B} \geq 41$} \\
\hline Oral CS & $0.92[0.39 ; 2.15]$ & \multirow{2}{*}{0.74} & $1.02[0.56 ; 1.84]$ & \multirow{2}{*}{0.05} \\
\hline Inhaled CS & $0.81[0.46 ; 1.40]$ & & $1.65[1.10 ; 2.47]$ & \\
\hline
\end{tabular}

Fully adjusted $^{\mathrm{d}}$

$\Delta$ TMTB $\geq 41$

Oral CS

$1.02[0.56-1.86]$

Inhaled CS

$1.76[1.14-2.71]$

0.04

${ }^{a}$ This corresponded to lowest quintile of performances, i.e. a decrease from baseline of at least 6 points on the Isaacs total score or at least two points on the Benton test and the MMSE and an increase from baseline of at least 15 (TMTA) or 41 seconds (TMTB).

${ }^{\mathrm{b}}$ Except for TMTA and TMTB, where $\mathrm{n}=2349$ for men and 3736 for women.

${ }^{\mathrm{c}}$ Adjusted for centre, age, education, and baseline cognitive performance.

${ }^{\mathrm{d}}$ Adjusted for centre, age, education, baseline cognitive performance, depression, ischemic pathologies, diabetes, hypercholesterolemia, caffeine, smoking, APOE\&4, chronic joint or back pain, chronic bronchitis, asthma and other chronic respiratory disorders.

MMSE $=$ Mini-Mental State Examination; TMTA = Trail Making Task A; TMTB = Trail Making Task B. 
Table 3. Cognitive decline in executive function in women according to pattern of inhaled corticosteroid use during the follow-up period $\left(n=3231^{a}\right)$

Minimally adjusted $^{\mathrm{b}} \quad$ Fully adjusted $^{\mathrm{c}}$

OR $(95 \% \mathrm{CI}) \quad p \quad$ OR $(95 \% \mathrm{CI}) \quad p$

\section{$\Delta \mathrm{TMTB} \geq 41$}

$$
\text { None }^{\mathrm{d}}
$$

Discontinuing

$1.39[0.69 ; 2.77]$

0.36

$3.01[1.24 ; 7.26] \quad 0.01$

Continuing
1

$1.41[0.69 ; 2.89] \quad 0.35$

${ }^{a}$ The 505 women having taken inhaled CS intermittently during the follow-up or having taken oral $\mathrm{CS}$ at baseline or during the follow-up were not considered in this analysis.

${ }^{\mathrm{b}}$ Adjusted for centre, age, education, and baseline cognitive performance.

${ }^{c}$ Adjusted for centre, age, education, baseline cognitive performance, depression, ischemic pathologies, diabetes, hypercholesterolemia, caffeine, smoking, APOE 84 , chronic joint or back pain, chronic bronchitis, asthma and other chronic respiratory disorders.

d. Nonusers of oral and inhaled corticosteroids during 7 years TMTB $=$ Trail Making Task B 
Table 4. Baseline NSAID use and cognitive decline over the 7-year follow-up period

\begin{tabular}{llccc}
\hline & $\begin{array}{l}\text { MEN }\left(\mathbf{n}=\mathbf{2 8 3 3}{ }^{\mathrm{a}}\right) \\
\text { OR }[95 \% \mathrm{CI}]^{\mathrm{b}}\end{array}$ & $p$ & ${\text { OR }[95 \% \mathrm{CI}]^{\mathrm{b}}}^{\mathrm{O}}$ & $p$ \\
\hline$\Delta$ MMSE $\leq-2$ & $1.11[0.81 ; 1.53]$ & 0.52 & $0.92[0.75 ; 1.14]$ & 0.45 \\
$\Delta$ Benton $\leq-2$ & $1.07[0.76 ; 1.49]$ & 0.71 & $0.99[0.80 ; 1.24]$ & 0.95 \\
$\Delta$ Isaacs $\leq-6$ & $0.92[0.66 ; 1.29]$ & 0.64 & $1.17[0.95 ; 1.44]$ & 0.15 \\
$\Delta$ TMTA $\geq 15$ & $1.09[0.74 ; 1.59]$ & 0.67 & $1.09[0.86 ; 1.39]$ & 0.47 \\
$\Delta$ TMTB $\geq 41$ & $1.04[0.70 ; 1.54]$ & 0.84 & $1.12[0.89 ; 1.42]$ & 0.34
\end{tabular}

${ }^{\mathrm{a}}$ Except for TMTA and TMTB, where $\mathrm{n}=2349$ for men and $\mathrm{n}=3736$ from women.

${ }^{\mathrm{b}}$ adjusted for centre, age, education, and baseline cognitive performance.

MMSE $=$ Mini-Mental State Examination; BVRT $=$ Benton Visual Retention Test; TMTA $=$ Trail Making Task A; TMTB = Trail Making Task B. 
Table 5. Baseline CS and NSAID use and 7-year incidence of dementia (Cox model with delayed entry)

Women $(\mathrm{n}=4573)$

$\mathrm{HR}^{\mathrm{a}}(95 \% \mathrm{CI})$
Men (n=2913)

$\mathrm{HR}^{\mathrm{a}}(95 \% \mathrm{CI}) \quad p$

CS
All dementia ${ }^{b}$
$1.22(0.72 ; 2.06)$
0.45
$0.91(0.50 ; 1.67)$
0.76
Alzheimer's disease ${ }^{c}$
$1.21(0.64 ; 2.28)$
0.55
$0.74(0.33 ; 1.63)$
0.45

NSAID
All dementia ${ }^{b}$
$1.27(0.88 ; 1.83)$
0.20
$0.88(0.48 ; 1.63)$
0.69

Alzheimer's disease $^{c}$

$1.32(0.86 ; 2.03)$

0.21

$1.01(0.49 ; 2.09)$

0.97

\footnotetext{
${ }^{a}$ Adjusted for gender, centre, age, education, depression, ischemic pathologies, diabetes, hypercholesterolemia, caffeine, smoking, APOE $\varepsilon 4$, chronic joint or back pain, chronic bronchitis, asthma and other chronic respiratory disorders.

b 320 women and 207 men were diagnosed with incident dementia.

' 226 women and 134 men had incident Alzheimer's disease. The 94 women and 73 men with other types of dementia were excluded from this analysis.
} 
eTable 1. Frequency of use of CS according to formulation mode among study 7234 participants*

\begin{tabular}{lcl}
\hline CHEMICAL ACTIVE SUBSTANCE & n & Frequency (\%) \\
\hline ORAL CS (n=123) & & \\
BETAMETHASONE & 7 & 1.79 \\
CORTISONE & 4 & 1.03 \\
CORTIVAZOL & 3 & 0.77 \\
DEXAMETHASONE & 2 & 0.51 \\
FLUDROCORTISONE & 1 & 0.26 \\
HYDROCORTISONE & 9 & 2.31 \\
METHYLPREDNISOLONE & 11 & 2.82 \\
PREDNISOLONE & 19 & 4.87 \\
PREDNISONE & 63 & 16.15 \\
TRIAMCINOLONE & 4 & 1.03 \\
\hline INHALED CS (n=267) & & \\
BECLOMETASONE & 107 & 27.43 \\
BUDESONIDE & 80 & 20.52 \\
FLUNISOLIDE & 4 & 1.03 \\
FLUTICASONE & 47 & 12.06 \\
PREDNISOLONE & 1 & 0.26 \\
TIXOCORTOL & 5 & 1.29 \\
TRIAMCINOLONE & 23 & 5.90 \\
\hline
\end{tabular}

*38 subjects were using more than one CS medication. 
eTable 2. Frequency of use of NSAID (n=675) among study 7234 participants*

\begin{tabular}{|c|c|c|}
\hline CHEMICAL ACTIVE SUBSTANCE & $\mathrm{n}$ & Frequency $(\%)$ \\
\hline ALMINOPROFEN & 1 & 0.15 \\
\hline CELECOXIB & 37 & 5.48 \\
\hline DIACEREIN & 156 & 23.11 \\
\hline DICLOFENAC & 98 & 14.52 \\
\hline ETODOLAC & 8 & 1.19 \\
\hline FENBUFEN & 1 & 0.15 \\
\hline FENOPROFEN & 9 & 1.33 \\
\hline FLURBIPROFEN & 11 & 1.63 \\
\hline GLUCOSAMINE & 1 & 0.15 \\
\hline IBUPROFEN & 58 & 8.59 \\
\hline INDOMETHACIN & 4 & 0.59 \\
\hline KETOPROFEN & 67 & 9.93 \\
\hline MELOXICAM & 10 & 1.48 \\
\hline MORNIFLUMATE & 2 & 0.3 \\
\hline NABUMETONE & 8 & 1.19 \\
\hline NAPROXEN & 26 & 3.85 \\
\hline NIFLUMIC ACID & 7 & 1.04 \\
\hline NIMESULIDE & 16 & 2.37 \\
\hline OXACEPROL & 13 & 1.93 \\
\hline PIROXICAM & 96 & 14.22 \\
\hline ROFECOXIB & 9 & 1.33 \\
\hline SULINDAC & 8 & 1.19 \\
\hline TENOXICAM & 25 & 3.7 \\
\hline TIAPROFENIC ACID & 2 & 0.3 \\
\hline
\end{tabular}

*43 subjects were using more than one NSAID medication. 